\title{
Padrões de organização do sistema de comunicação mãe-bebê nas interações face a face: estudo de cinco díades
}

\author{
Maria da Conceição Diniz Pereira de Lyra \\ Universidade Federal de Pernambuco \\ Emmanuelle Christine Chaves da Silva \\ Universidade Federal de Pernambuco \\ Faculdade dos Guararapes \\ Faculdade Maurício de Nassau \\ Ana Claudia Alves da Silva \\ Universidade Federal de Pernambuco
}

\begin{abstract}
Resumo
Apresentamos os que emergem do processo de desenvolvimento da comunicação mãe-bebê nas interações do tipo face a face. Este processo é concebido como compondo um sistema dinâmico em constante transformação e construção. Os padrões de organização descrevem as fases de maior estabilidade desse sistema, propostas pelo modelo EEA como constituindo três padrões que se sucedem: um estabelecimento inicial, seguido de um período de extensão e, finalmente, um período de abreviação das trocas comunicativas. Analisamos os dados longitudinais das trocas comunicativas do tipo face a face de cinco díades mãe-bebê, descrevendo o processo através do qual esses padrões se organizam. Identificamos uma tendência geral de manutenção da mesma sequência de aparecimento e dominância desses três padrões nas cinco díades, tal como proposto pelo modelo EEA. Todavia, cada díade difere na idade de aparecimento, de dominância e na duração de cada um dos padrões referidos.
\end{abstract}

Palavras-chave: modelo EEA; interações face a face; padrões de organização; comunicação mãe-bebê.

\begin{abstract}
Patterns of organization of the mother-infant communication in face-to-face interactions: The study of five dyads. We present the patterns of organization that emerge from the developmental process of mother-infant communication in face-to-face exchanges. This process is conceived as creating a dynamic system in constant transformation and construction. The patterns of organization describe the periods of stability of this system, proposed by the EEA model as corresponding to three successive patterns, starting by an initial establishment, followed by a period of extension, and finally by an abbreviation of the dyadic exchanges. We analyzed the longitudinal mother-infant face-to-face exchanges from five dyads, describing the process of organization of these patterns. We identified a general tendency toward maintenance of the sequence of emergence and dominance of these three patterns in all five dyads, according to the proposals of the EEA model. However, each dyad differs in terms of age of appearance, dominance and duration of each of these patterns.
\end{abstract}

Keywords: EEA model; face to face interactions; patterns of organization; mother-infant communication.

$\mathrm{O}$ S estudos do desenvolvimento da comunicação mãe-bebê podem ser agrupados de acordo com dois grandes conjuntos de trabalhos, não, necessariamente, excludentes. Um primeiro diz respeito àqueles que examinam as primeiras trocas com o parceiro como fonte de emergência e desenvolvimento das habilidades sociais, do desenvolvimento emocional, da construção do apego e, finalmente, da aquisição da linguagem (por exemplo, Bornstein \& Tamis-LeMonda, 2001). Estas investigações utilizam o termo interação e, em geral, se baseiam em estudos observacionais com registros em vídeo das trocas entre mãe e bebê/criança. Tais estudos se destacam por usar categorias, tais como a responsividade materna a diferentes formas de estresse do bebê ou buscar a elaboração de categorias que descrevam as ações da mãe (ou parceiro adulto) e as ações do bebê/criança (por exemplo, Piccinini \& Seidl-De-Moura, 2007, representam esta tendência). Por exemplo, estudar a responsividade materna a partir de categorias de análise, tais como: vocalização com estresse e vocalização sem estresse (atividades do bebê) e fala ou vocalização, estimulação diádica, estimulação extradiádica (atividades da mãe) (Ribas \& Seidl de Moura, 2006). Essas categorias, no entanto, separam em unidades discretas ambos os parceiros e suas ações e podem, assim, conduzir o pesquisador a perder de vista a relação, ou seja, o processo de mútua transformação e interdependência das 
ações dos parceiros ao longo do tempo que caracteriza o sistema de comunicação em desenvolvimento (Fogel, Garvey, Hsu, \& West-Stroming, 2006).

Um segundo grupo de estudos, que prefere o uso do termo comunicação, tem como ponto de destaque o estudo das trocas entre os parceiros examinando a emergência e desenvolvimento da intersubjetividade (Bråten, 1998). O destaque está na qualidade das trocas diádicas enquanto refletem, ou permitem inferir, a emergência do bebê como um sujeito, indivíduo, eu ou self (Tomasello, 2008). As características afetivo-emocionais ou cognitivas e a discussão sobre o caráter herdado versus adquirido da comunicação no início da vida (tal como, se o bebê humano nasce capacitado para estabelecer uma troca dialógica ou esta somente ocorre a partir da aquisição de linguagem) são, em geral, abordadas como aspectos que marcam as diferenças entre as posições adotadas acerca da subjetividade e intersubjetividade humanas (Tomasello, Carpenter, Call, Behne, \& Moll, 2005).

É importante referir, ainda, que o desenvolvimento dos registros em vídeo em conjunto com recursos computacionais possibilitaram um aumento crescente da utilização de técnicas de análise microanalíticas das trocas mãe-bebê ${ }^{1}$, sobretudo nos últimos anos (Fogel et al., 2006; Lavelli, Pantoja, Hsu, Messinger, \& Fogel, 2005; Lyra, 2006; Lyra, 2007b; Lyra \& Bertau, 2008). Este avanço técnico passou a ser utilizado amplamente, de forma independente da perspectiva teóricometodológica adotada.

Os pesquisadores brasileiros têm demonstrado um interesse crescente neste tema, ou, de forma mais ampla, na investigação da primeira infância. São tratados temas e metodologias diversas versando sobre as interações bebê/criança e seus pais. Destacamos, particularmente, os trabalhos desenvolvidos pelo grupo Interação Pais-Bebê/Criança da Anpepp, particularmente, Bosa (Sanini, Ferreira, Souza, \& Bosa, 2008), Lordelo (Lordelo \& Carvalho, 2006), Piccinini (Piccinini, Marin, Alvarenga, Lopes, \& Tudge, 2007), Salomão (Fonseca \& Salomão, 2006), Schermann (Alfaya \& Schermann, 2005) e Seidl de Moura em parceria com outros (Seidl de Moura et al., 2008).

Nos últimos dez anos, Rossetti-Ferreira em parceria com outros pesquisadores (Dos Anjos, Amorim, Vasconcelos, \& Rossetti-Ferreira, 2004; Rossetti-Ferreira, Amorim, Silva, Carvalho, \& 2003; Vasconcelos \& Rossetti-Ferreira, 2002;) têm investigado a interação social em ambiente de creche. RossettiFerreira, Amorim e Silva (2000) destacam ser o ingresso na creche um momento profícuo para a investigação das interações que envolvem o bebê, a família e os educadores da creche, sendo possível apreender os processos de construção e as mútuas transformações dos sujeitos naquela situação. As autoras apresentam uma nova perspectiva teórico-metodológica de estudo que propõe uma "rede de significações", de configuração semiótica, para compreender o desenvolvimento humano.

Ainda, outra linha de investigação sobre a relação adultobebê/criança frequente nos estudos realizados no Brasil, é aquela que tem como base teórico-metodológica, de forma mais ou menos enfática, a abordagem psicanalítica. Embora constatemos a existência de diferentes linhas de estudo baseadas nesta abordagem, daremos destaque ao grupo composto por De Lemos (2003), Lier-De Vitto (2005), Carvalho (2003) e Arantes
(Lier-DeVitto \& Arantes, 2006). Este grupo focaliza a aquisição da linguagem, e apresenta uma concepção específica sobre o interacionismo que, segundo Vitto e Carvalho (2008), concebe as primeiras trocas adulto-criança como tendo papel primordial no processo de subjetivação do sujeito, marcado pelo entendimento de uma posição inicial da criança em "alienação" ao outro. Esta "alienação" se refere à dependência dialógica da fala da criança à fala do adulto. Assim, o processo de subjetivação ocorre inserido na própria linguagem (Vitto \& Carvalho, 2008).

O presente trabalho se insere nas investigações desenvolvidas no Laboratório de Comunicação e Linguagem na Primeira Infância - LabCom - da Universidade Federal de Pernambuco. Nele, os estudos sobre o desenvolvimento da comunicação mãebebê estão fundamentados na perspectiva dos sistemas dinâmicos e na abordagem dialógica. Lyra e colaboradores propõem um modelo de análise e compreensão do processo de comunicação mãe-bebê que focaliza a relação entre esses parceiros ao longo do tempo e é denominado de modelo EEA por integrar os conceitos de estabelecimento, extensão e abreviação (Lyra, 2000; Lyra \& Bertau, 2008; Lyra \& Chaves, 2000; Lyra \& Winegar, 1997). Tanto a perspectiva dos sistemas dinâmicos como o modelo EEA serão apresentados a seguir.

A perspectiva dos sistemas dinâmicos, o modelo EEA e o estudo do desenvolvimento do processo de comunicação mãe-bebê

\section{Os sistemas dinâmicos}

Nos últimos anos tem crescido o interesse dos estudiosos em adotar uma perspectiva sistêmica do desenvolvimento (Bronfenbrenner, 1979; Fogel, 1993; Lewis, 2000; van Geert, 1994). Parte deles tem se dedicado a investigar algumas propriedades gerais dos sistemas dinâmicos (SDs), que se modificam ao longo do tempo porque são sistemas abertos (em constante interação com o meio no qual estão inseridos). Eles são chamados também de sistemas complexos e apresentam um paralelismo tanto com sistemas encontrados na Física como com aqueles reconhecidos na Biologia (Progogine \& Stengers, 1984; van Geert, 2003). As propriedades desses sistemas, descritas, por exemplo, através dos conceitos de auto-organização, padrões de organização, estados-espaço, atratores e transições de fase, têm sido cuidadosamente investigadas e aplicadas em diversos modelos do desenvolvimento humano (Fogel, 1993; Fogel \& Lyra, 1997; Lewis, 2000; Lyra, 2007a; Thelen, Schoner, Scheier, \& Smith, 2001; van Geert, 1998). A abordagem dos SDs aplicada à análise e compreensão do desenvolvimento humano, oferecenos um arcabouço útil para a compreensão do processo através do qual o ser humano se desenvolve ao longo de todo o ciclo de vida, podendo focalizar diversos aspectos deste processo.

\section{$O$ modelo EEA}

Adotando os fundamentos da perspectiva dos SDs, a comunicação entre a mãe e seu bebê é concebida como um processo contínuo e corregulado (Fogel, 1993). A compreensão de um processo contínuo é mais claramente obtida se contraposta à ideia de processo discreto. Um processo discreto é aquele que separa, analiticamente, o emissor, a mensagem e o receptor. 
Por sua vez, um processo contínuo entende que todas estas três dimensões da comunicação são impossíveis de separar analiticamente porque compõem um todo relacional, ou seja, um sistema de relações. O que esta posição quer dizer é que o emissor, o receptor e a própria mensagem, são transformados no transcorrer da negociação das trocas. Desta forma, nunca poderemos analisar, separadamente, estes três aspectos. O que temos de investigar e compreender são as relações entre eles ao longo do tempo. Temos que nos deter no discernimento dos mecanismos através dos quais estes três elementos se corregulam. Mais ainda, devemos identificar os diferentes padrões de organização que estas corregulações fazem emergir ao longo do desenvolvimento, ou seja, nas formas assumidas pelas negociações entre os parceiros comunicativos.

O modelo EEA propõe que o processo de comunicação mãebebê seja construído obedecendo a uma sequência de padrões de organização que apresentam complexidade crescente e que se distinguem pelas diferentes características das trocas mãe-bebê. Estas trocas, sem a mediação do objeto (trocas face a face ou FF) ou com esta mediação (trocas mãe-objeto-bebê ou MOB), exibem níveis desenvolvimentistas que possibilitam incluir os aspectos generalizáveis e as particularidades presentes em cada díade mãe-bebê estudada (Molenaar \& Valsiner, 2005). Ambos são inerentes à história de cada díade. Cada um desses padrões exibe um tipo característico de negociação entre os parceiros que se aplica tanto às trocas FF como MOB.

O estabelecimento, a extensão e a abreviação compõem um conjunto de três conceitos que representam os processos subjacentes ao desenvolvimento da comunicação mãe-bebê, nos primeiros oito meses de vida pós-natal do bebê. Estes processos se caracterizam por uma dinâmica entre os parceiros que exerce uma atividade de recorte, destaque, diferenciação ou "escolha", a qual chamamos de dinâmica dialógica de recorte (Lyra, 1998) conceito que teve sua origem nas ideias de De Lemos (1981, 1985).

A dinâmica dialógica de recorte propõe que a interação entre parceiros ocorre através do destaque ou recorte de pelo menos uma ação (ou conjunto de ações) que se torna objeto de negociação. Além disto, e destacando o caráter relacional da atividade de recorte aplicado sobre o fluxo de ações dos parceiros, utilizamos uma analogia relativa à ideia de figurafundo originária dos estudos de percepção; a díade "escolhe" pelo menos uma dessas ações (ou conjunto de ações) para que se torne "figura" em relação ao fluxo constante e complexo de outras ações dos parceiros, que adquirem a função de "fundo". Os conceitos de estabelecimento, extensão e abreviação estão baseados nas características construtivas desta atividade de recorte. Eles constituem padrões de organização que foram historicamente construídos a partir dessas sucessivas atividades efetuadas pela díade mãe-bebê; possibilitam abarcar, em nível macroanalítico, etapas do desenvolvimento desse sistema de comunicação na faixa etária focalizada.

Considerando esta atividade construtiva, podemos assim definir o estabelecimento, a extensão e a abreviação:

\section{Estabelecimento}

Através de sucessivas ou concomitantes ações dos parceiros, que "recortam" o fluxo de atividades da díade, pelo menos uma ação das trocas diádicas é construída de forma partilhada pela díade. Esta ação se torna "figura" em relação a um "fundo" de outras ações realizadas pela díade. Por exemplo, o olhar mútuo entre os parceiros, nas trocas face a face. São trocas de curta duração - inferior ou igual a 6 turnos $^{2}$. Além disso, tais trocas não são imediatamente estabelecidas nem suavemente ajustadas (Lyra \& Souza, 2003).

\section{Extensão}

As ações previamente estabelecidas tornam-se um "fundo" em relação ao qual a díade pode "recortar" e negociar, elaborando de modo mais prolongado outras ações como "figuras". Por exemplo, nas trocas face a face, tendo estabelecido o contato de olhar mútuo, podem ser negociados sorrisos, vocalizações, movimentos etc., de forma elaborada e prolongada - superior a 6 turnos. As trocas passam a ser imediatamente estabelecidas e a suavidade dos ajustes mútuos vai crescendo no decorrer do período da extensão.

\section{Abreviação}

Trocas de curta duração - inferior ou igual a 6 turnos executadas pela díade através de um ajustamento mútuo rápido e fácil, em que as ações anteriormente negociadas e trabalhadas pela díade, de forma prolongada, aparecem de modo reduzido ou condensado (abreviados). Por exemplo, considerando as trocas face a face, a díade utiliza um rápido contato de olhar acompanhado ou não de algumas ações anteriormente negociadas (sorriso, movimentos, por exemplo). As trocas são imediatamente estabelecidas, suaves e de curta duração.

\section{Método}

\section{As díades mãe-bebê}

As mães foram convidadas a participar de um estudo sobre o desenvolvimento do bebê, no qual ela deveria estar presente. Solicitou-se à mãe que agisse "como se estivesse em casa", brincando ou cuidando do bebê como naturalmente o faz quotidianamente. As cinco díades que participaram deste estudo tinham nível socioeconômico médio, bebês nascidos a termo que apresentaram um desenvolvimento considerado normal, segundo exames pediátricos regulares. As mães estavam na faixa etária entre 20 e 35 anos e não apresentavam qualquer queixa ou característica de distúrbios psicológicos específicos. Todas eram casadas, moravam com seus respectivos maridos e desenvolviam uma atividade profissional que permitia a elas dedicar-se aos cuidados do bebê durante, pelo menos, um turno ao dia. No que diz respeito aos bebês, quatro eram do sexo masculino e apenas um do sexo feminino. Além disso, apenas um dos bebês era o segundo filho do casal, enquanto todos os outros eram primogênitos.

\section{Os registros em vídeo}

Foram realizados registros semanais em vídeo no Laboratório de Comunicação e Linguagem na Primeira Infância (LabCom) de cinco díades mãe-bebê. A coleta de dados foi iniciada no 
momento em que a mãe se dispôs a participar do estudo. Disto resultou que a idade inicial dos bebês na primeira semana de registro variou de 6 a 11 semanas. O final dos registros se deu no momento em que foi observado que a díade apresentava, em três registros consecutivos (no mínimo), o predomínio (acima de $50 \%$ do tempo dedicado às trocas interacionais) do padrão de abreviação das trocas mãe-bebê do tipo face a face. Desta forma, a idade dos bebês variou de 26 a 35 semanas de vida, em relação à finalização da coleta dos dados.

Os registros semanais de aproximadamente 20 minutos cada, foram efetuados no LabCom por um estudante colaborador (aluno de iniciação científica), o qual ficava no laboratório e procurava realizar os registros focalizando as atividades realizadas pela díade. Estes registros foram efetuados em VHS, contendo uma marcação temporal de centésimos de segundo, e, posteriormente, foram digitalizados e transferidos para mídias de DVD.

O laboratório de coleta de dados do LabCom é mobiliado como uma sala de estar decorada com motivos infantis, contendo: uma poltrona, um tapete, brinquedos próprios para a faixa etária do bebê espalhados pelo tapete, ar-condicionado, cortina, quadros e enfeites infantis.

\section{A análise dos dados}

Visando a identificação dos padrões de organização do sistema de comunicação mãe-bebê - estabelecimento, extensão e abreviação - descreveremos as sucessivas etapas que guiaram a análise dos registros videográficos ${ }^{3}$.

Etapa 1: sensibilização. Esta etapa visa sensibilizar o observador-pesquisador acerca dos registros. A instrução dada neste momento é a de que, tendo em mente que o objetivo do estudo focaliza as trocas mãe-bebê ao longo do tempo, "assista aos registros sem compromisso de identificar nem de realizar qualquer marcação, até que se sinta à vontade para identificar qualquer coisa em relação às trocas mãe-bebê". Durante esta etapa, progressivamente é solicitado do observador-pesquisador que focalize sua atenção "no que mudou nas trocas mãe-bebê", considerando o transcorrer dos registros ao longo do tempo, sem ser necessário precisar, ainda, "o que mudou”. Em toda esta etapa é o observador-pesquisador que escolhe se deseja "retornar", "pausar", adiantar" e/ou, simplesmente, "prosseguir" assistindo aos registros videografados.

Etapa 2: classificação dos episódios de FF. Agora é solicitado do observador-pesquisador que identifique as trocas mãe-bebê FF com base na seguinte definição deste tipo de troca: as trocas FF caracterizam trocas entre os parceiros que se acham em posição capaz de estabelecerem o contato de olhar sem a inclusão explícita de nenhum elemento do mundo que os cerca mediando essas trocas. O início do episódio FF é delimitado pelo estabelecimento do contato olho-a-olho entre os parceiros e o final do episódio se dá pela interrupção deste contato por qualquer um dos parceiros que exceda o intervalo de cinco segundos. Estes limites são anotados a partir da marcação temporal dos registros, considerando centésimos de segundos. Assim, ligeiras "quebras" do contato de olhar são permitidas.
Este intervalo de cinco segundos é arbitrário e resultou da experiência empírica acumulada pelas pesquisas realizadas no LabCom (Lyra, 2000; Lyra \& Chaves, 2000). O que subjaz a esta experiência é que se infere uma continuidade do episódio mesmo que haja este intervalo de interrupção. Acima de cinco segundos, parece se configurar em outro episódio. Todos os registros são classificados exaustivamente, colocando-se, nos trechos nos quais não é possível discernir as trocas FF, a classificação de "outros".

Também nesta etapa é o observador-pesquisador que escolhe o quanto deseja retornar, pausar e/ou, simplesmente, prosseguir assistindo aos registros videografados. Todavia, agora é imprescindível tanto a "pausa" como o movimento comparativo, que exige tanto o "retorno" como o "adiantamento" dos registros videografados.

Etapa 3: episódios de trocas FF classificados como estabelecimento, extensão ou abreviação. O passo seguinte diz respeito à classificação de cada episódio de troca FF, anteriormente identificado, como apresentando as características do estabelecimento, da extensão ou da abreviação, tendo como base as definições anteriormente apresentadas destes padrões de organização das trocas mãe-bebê.

Etapa 4: identificação da "preferência" do sistema de comunicação mãe-bebê em apresentar as características do estabelecimento, da extensão ou da abreviação: sua configuração dominante. Estipulamos considerar que a percentagem de tempo no qual a díade "escolhe" realizar trocas classificadas como estabelecimento, extensão ou abreviação diz da "preferência" do sistema de comunicação mãe-bebê em funcionar nestes diferentes níveis de organização. Ainda mais, consideramos uma percentagem acima de 50\% como apontando o predomínio do estabelecimento, da extensão ou da abreviação e, assim, adquire uma característica de padrão de organização preferido ou adotado pelo sistema em questão.

\section{Resultados}

Os resultados encontrados para as cinco díades analisadas acham-se apresentados na figura 1. Essa figura traz a ilustração dos gráficos obtidos, para as cinco díades, na análise dos padrões de organização das trocas face a face: estabelecimento, extensão e abreviação.

Podemos organizar estes resultados de acordo com os seguintes aspectos: (a) o que encontramos de comum entre todas as díades em relação aos padrões de organização e (b) as particularidades de cada díade no que se refere aos referidos padrões.

Um primeiro aspecto geral que pode ser destacado nos gráficos das cinco díades analisadas está relacionado à ordem de sucessão dos padrões de organização identificados.

Em relação ao padrão de estabelecimento, o mesmo foi identificado nos primeiros registros das trocas mãe-bebê (primeiro ponto no gráfico no eixo das ordenadas) de quatro 


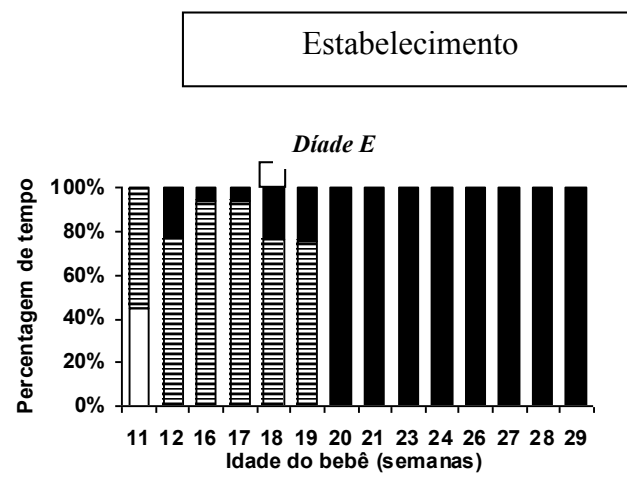

Extensão $\quad$ Abreviação

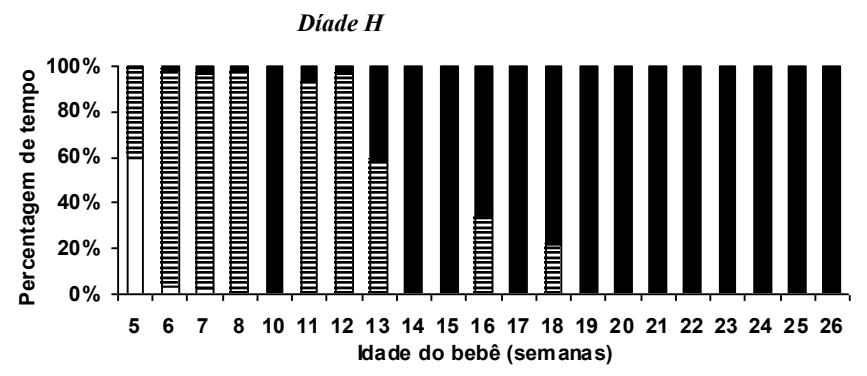

Díade I
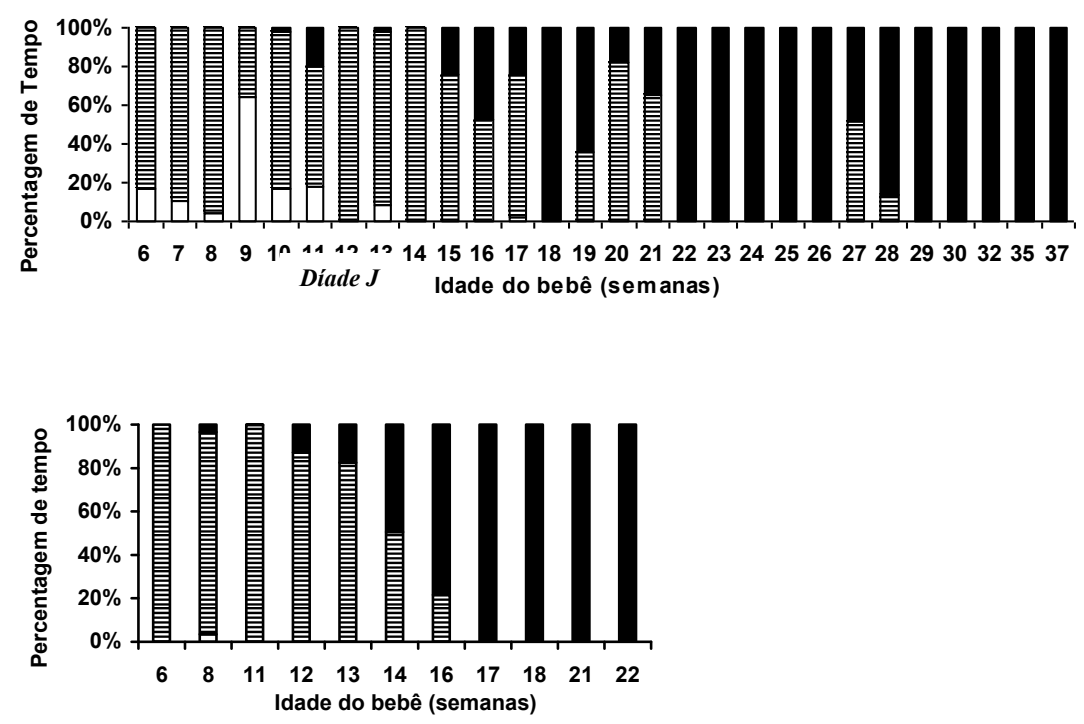

Figura 1. Percentagens de tempo de ocorrência dos padrões de Estabelecimento, Extensão e Abreviação nas interações "Face a Face" em função da idade do bebê nas díades E, F, H, I e J

dentre as cinco díades analisadas $(44,83 \%$ na díade $\mathrm{E} ; 100 \%$ na díade $\mathrm{F} ; 59,75 \%$ na díade $\mathrm{H}$ e $16,3 \%$ na díade I). Apesar desta variação, é possível sugerir que no início do desenvolvimento da comunicação é necessário que um primeiro elemento comunicativo seja estabelecido como ponto de partida para que, em seguida, outros elementos possam ser negociados durante um tempo mais extenso; permitindo, assim, que as trocas comunicativas entre a mãe e o bebê, progressivamente, tornemse mais elaboradas. Outra consideração sobre a emergência do padrão de estabelecimento deve ser feita. No início dos registros, o sistema de comunicação mãe-bebê parece exibir uma certa instabilidade, de modo que, em algumas díades - embora existam trocas em que o objetivo principal é a negociação de um primeiro elemento comunicativo (trocas de estabelecimento), tal padrão de troca não apresenta um predomínio (percentual do tempo despendido pela díade acima de 50\%) em nenhuma das díades investigadas.

Um exemplo disto pode ser observado no gráfico da Díade 
I. Nesta, o tempo dedicado às trocas caracterizadas como estabelecimento não chegam aos $20 \%$ nos registros realizados aos seis, sete e oito semanas de vida do bebê. Todavia, este tempo parece ser suficiente para que a díade possa estabelecer o olhar entre a mãe e o bebê, como primeiro elemento da comunicação e, em seguida, possa começar a negociar, como figura, outros elementos comunicativos, tais como sorrisos, vocalizações, movimentos corporais, etc. Um indício disto é o percentual de tempo que a díade passa a dedicar, já nestas primeiras semanas de registro, às trocas caracterizadas como extensão (40,24\%, na $6^{\mathrm{a}}$ semana de vida do bebê).

No caso da Díade J, a qual foi a única díade em que o tempo dedicado às trocas com características do padrão de estabelecimento é quase inexistente no início dos registros, uma ressalva deve ser feita. Como dito anteriormente, o início da coleta de dados é feita quando a mãe se disponibiliza a realizar as visitas ao laboratório de coleta de dados do LabCom. Em relação à referida díade, o início da coleta ocorreu quando o bebê tinha seis semanas de vida. $\mathrm{O}$ fato de as análises terem apontado que neste período já predominam as trocas caracterizadas como extensão pode significar que, nesta díade, o período de maior dedicação ao estabelecimento de um primeiro elemento comunicativo (padrão de estabelecimento) ocorreu antes da sexta semana de vida do bebê; embora seja possível identificar um percentual de $3,4 \%$ do tempo dedicado por esta díade às trocas com características de estabelecimento, na $8^{\underline{a}}$ semana de vida do bebê.

Ainda a partir dos gráficos apresentados pela figura 1, podemos perceber que o padrão de extensão emerge e predomina como forma de configuração das trocas diádicas, dando lugar, em seguida, ao predomínio do padrão de abreviação. Isto pode ser observado, por exemplo, na díade E, na $12^{\underline{a}}$ semana de vida do bebê, quando $77,05 \%$ das trocas diádicas se configuram como extensão, e apenas $22,95 \%$ apresentam como configuração o padrão de abreviação. O predomínio do padrão de extensão em relação àqueles de estabelecimento e abreviação também pode ser identificado na $12^{\underline{a}}$ semana de vida do bebê, na díade $\mathrm{F}$ (extensão - 68,75\%, abreviação - 31,25\% e nenhum percentual de tempo dedicado ao estabelecimento); na $6^{\underline{a}}$ semana, na díade $\mathrm{H}$ (extensão - 94,83\%, estabelecimento - 3,34\% e abreviação - $1,81 \%$ ) e na $10^{\mathrm{a}}$ semana, na díade I (extensão $80,6 \%$, estabelecimento - $16,4 \%$ e abreviação - 2,0\%). Isto quer dizer que a mãe e o bebê, neste momento do desenvolvimento, dedicam-se a expandir as possibilidades das trocas comunicativas através da negociação de elementos comunicativos que, até então, não haviam sido negociados como figura durante as trocas diádicas.

Além disso, o padrão de extensão exibe uma característica diferente do padrão de estabelecimento, no que diz respeito ao período de identificação de tal padrão ao longo das semanas de vida do bebê. Enquanto o padrão de estabelecimento pode ser identificado nos registros iniciais e durante um curto período de tempo, entre a $5^{\mathrm{a}}$ e a $8^{\mathrm{a}}$ semana de vida dos bebês, o período quando é possível identificar o padrão de extensão (e o seu predomínio) parece ser mais longo. Esta tendência pode ser observada no gráfico da díade $\mathrm{J}$, por exemplo, no qual o predomínio do padrão de extensão (percentual de tempo maior que $50 \%$ ) se inicia na sexta semana de vida do bebê, com $100 \%$ do tempo da díade destinado às trocas de extensão, e perdura até a $13^{\underline{a}}$ semana com $82,3 \%$. O mesmo pode ser destacado nos gráficos das díades E e I, quando o predomínio do referido padrão de organização ocorre entre a 11a e 19a semana de vida do bebê e entre a 6 a e 17 a semanas, respectivamente.

Embora seja possível identificar esta característica do padrão de extensão em todas as díades aqui analisadas, percebemos que, cada díade, em função de suas particularidades, vai apresentar diferenças tanto em relação ao tempo dedicado à extensão em cada registro realizado (cada idade do bebê em semana), como no que diz respeito ao período de predomínio deste padrão de organização ao longo dos diversos registros.

A consolidação das trocas face a face caracterizadas como extensão abre caminho para que as díades mãe-bebê possam começar a exibir um padrão abreviado dessas trocas. Assim, na díade $\mathrm{H}$, as trocas abreviadas face a face começaram a ser identificadas na sexta semana de vida do bebê. Nesta oportunidade, apenas $1,81 \%$ do tempo foi dedicado ao padrão de abreviação. Além disso, há uma variação no tempo que esta díade destina às trocas abreviadas ao longo do tempo - $6,89 \%$ na 11 a semana; $3,93 \%$ na 12 a e $41,25 \%$ na $13 a$ - que perdura até a 19a semana de vida do bebê quando, nesta díade, a abreviação passa a dominar a configuração assumida pelas trocas face a face. No caso da díade J, entretanto, as trocas abreviadas começam a ser identificadas na oitava semana de vida do bebê e o percentual de tempo dedicado a este tipo de troca vai aumentando, gradualmente, ao longo dos registros (12,8\% na $12 \mathrm{a}$ semana, $17,5 \%$ na 13 a e $49,5 \%$ na 14 a semana). Mais uma vez os gráficos da figura 1 destacam que o início da caracterização das trocas como trocas abreviadas em cada díade é diferente, bem como as variações do tempo que a díade dedica à abreviação ao longo das semanas. Apesar disso, os gráficos também apontam que, a partir de um determinado período no desenvolvimento das trocas face a face, todas as díades apresentam como padrão dominante, isto é, $100 \%$ das trocas face a face, as trocas em forma de abreviação.

Tais resultados parecem apontar que as cinco díades analisadas exibem, em relação à sucessão dos padrões de organização das trocas face a face, uma mesma ordem, a qual é sugerida pelo modelo E-E-A como descrevendo o processo de mudança no desenvolvimento da comunicação no início da vida. Tal ordem aponta que, inicialmente, as trocas face a face se configuram de acordo com o padrão de estabelecimento, o qual é sucedido pelo padrão de extensão que, em seguida, dá lugar ao padrão de abreviação.

Além disso, os resultados aqui expostos ressaltam que as cinco díades, para alcançar cada padrão de organização aqui proposto, seguem uma trajetória diferente, marcada por variações que dizem da dinâmica particular que cada díade mãe-bebê vai construindo ao longo do tempo. Desta forma, o modelo E-E-A de investigação da comunicação mãe-bebê, além de discernir aspectos generalizáveis do processo de mudança ao longo do tempo, permite destacar as particularidades que cada díade mãe-bebê apresenta na sua construção da comunicação no 
início da vida.

\section{Considerações Finais}

O presente trabalho investigou o processo de desenvolvimento da comunicação entre a mãe e seu bebê nos primeiros meses de vida pós-natal do bebê considerando, especificamente, as interações do tipo face a face. Tratamos, assim, daquele tipo de interação direta, tipicamente observada no início do desenvolvimento das interações mãe-bebê, que não incluem objetos quaisquer e que parecem ter um cunho, basicamente afetivo-emocional. As mudanças na configuração das trocas FF que dizem respeito ao desenvolvimento das mesmas, foram abordadas a partir da aplicação dos três conceitos propostos pelo modelo EEA: estabelecimento, extensão e abreviação. Tais conceitos descrevem os padrões de organização que emergem, ao longo do tempo, das negociações entre mãe e bebê durante as trocas do tipo FF.

A utilização destes conceitos na análise empírica das trocas FF de cinco díades mãe-bebê brasileiras permitiu o discernimento tanto dos aspectos passíveis de generalização desse processo de desenvolvimento como das particularidades inerentes à construção desses padrões, em cada díade analisada.

É possível perceber de comum na dinâmica das trocas comunicativas das cinco díades que o primeiro padrão de organização que emerge no sistema de comunicação mãe-bebê é o estabelecimento. Todavia, a duração deste padrão, como configuração dominante do sistema de comunicação mãe-bebê, varia em cada díade. Isto quer dizer que, para cada uma das cinco díades é necessário um percentual de tempo diferente para o estabelecimento de um primeiro elemento comunicativo (o contato de olhar entre os parceiros diádicos), que permitirá o desenvolvimento e refinamento da comunicação entre a mãe e seu bebê.

As análises apontaram também de comum nas díades a emergência de um novo padrão de organização das trocas comunicativas que passa a ser exibido pelas díades mãe-bebê após o padrão de estabelecimento. Esse novo padrão é aquele de extensão, que corresponde às trocas diádicas que focalizam a negociação de diversos elementos comunicativos (sorrisos, vocalizações de ambos os parceiros, etc.) tendo como pano de fundo o contato de olhar, aquele primeiro elemento negociado anteriormente pela mãe e o bebê. Também, para todas as díades investigadas, este é o padrão de organização que mais perdura; o padrão de extensão perdura ao longo de várias semanas como configuração dominante do sistema de comunicação mãe-bebê nas cinco díades. Entretanto, este período tempo durante o desenvolvimento dedicado à extensão também é específico a cada díade investigada. Assim, a negociação de diversos elementos comunicativos como sorrisos, vocalizações, etc. , depende da história particular de cada díade, variando, assim, a sua duração em cada uma das cinco díades investigadas.

Por último, em todas as díades, emerge um terceiro padrão de organização nas trocas mãe-bebê investigadas, denominado pelo modelo EEA de abreviação. Como visto anteriormente, quando as trocas comunicativas mãe-bebê passam a exibir uma configuração abreviada, elas ocorrem num tempo mais curto e apresentam de maneira reduzida (abreviada, portanto) um ou mais elementos que já foram negociados pela mãe e pelo bebê em momentos anteriores (durante períodos de extensão). Além disso, todas as díades aqui consideradas mostraram que, uma vez que o padrão de abreviação passa a ser exibido como configuração dominante do sistema, ele perdura até o fim dos registros realizados para cada díade, ou seja, até a $29^{\mathrm{a}}$ semana de vida do bebê nas díades E e F; $26^{\underline{a}}$ semana na díade $\mathrm{H} ; 37^{\mathrm{a}}$ semana na díade I e $22^{\mathrm{a}}$ semana na díade $\mathrm{J}$.

A investigação do processo de desenvolvimento da comunicação mãe-bebê, ou seja, as características da sua dinâmica de construção, concebido como um sistema dinâmico nos oferece a oportunidade de compreender aquilo que este sistema apresenta de generalizável - seus padrões de organização - assim como a unicidade de cada díade, de cada sujeito envolvido no seu processo único de desenvolvimento. Desta forma, o geral e o particular podem ser conjuntamente investigados; esta é a principal contribuição do modelo EEA proposto para descrever e investigar o desenvolvimento da comunicação mãe-bebê.

\section{Referências}

Alfaya, C., \& Schermann, L. (2005). Sensibilidade e Aleitamento materno em díades com recém-nascidos de risco. Estudos de Psicologia, 10(2), 279-285.

Bornstein, M. H., \& Tamis-LeMonda, C. S. (2001). Mother-infant interaction. In G. Bremner \& A. Fogel (Orgs.), Blackwell handbook of infant development (pp. 269-295). Massachusetts: Blackwell Publishers.

Bråten, S. (1998). Intersubjectivity communion and understanding: development and perturbation. In S. Bråten (Orgs.), Intersubjective communication and emotion in early ontogeny (pp. 372-382). Cambridge: Cambridge University Press.

Bronfenbrenner, U. (1979). The ecology of human development: experiments by nature and design. Cambridge: Harvard University Press.

Carvalho, G. (2003). A exclusão da singularidade em questão: o erro como diferença em aquisição da Linguagem (Relatório de Pesquisa, Conselho Nacional de Desenvolvimento Científico e Tecnológico-CNPq).

De Lemos, C. T. G. (1981). Interactional processes in child's acquisition of language. In W. Deutsch (Org.), The child's construction of language (pp. 57-76). London: Academic Press.

De Lemos, C. T. G. (1985). Specularity as a constitutive process in dialogue and language acquisition. In L. Camaioni \& C. De Lemos (Orgs.), Questions on social explanation (pp. 23-31). Amsterdam: John Benjamins.

De Lemos, C. T. G., (2003). Corpo \& Corpus. In N. V. A. Leite (Org.), Corpo linguagem: Gestos e Afetos (pp. 21-29). Campinas: Mercado de Letras.

Dos Anjos, A. M., Amorim, K. S., Franchi e Vasconcelos, C. R., \& RossettiFerreira, M. C. (2004). Interações de bebês em creche. Estudos de Psicologia, 9(3), 513-522.

Fogel, A. (1993). Developing through relationships. Origins of communication, self and culture. Chicago: University of Chicago Press.

Fogel, A., Garvey, A. P., Hsu, H., \& West-Stroming, D. (2006). Change processes in relationships: relational-historical research on dynamic system of communication. Cambridge: Cambridge University Press.

Fogel, A., \& Lyra, M. C. D. P. (1997). Dynamics of development in relationships. In F. Masterpasqua \& P. Perna (Orgs.), The psychological meaning of chaos: translating theory into practice (pp. 75-94). Washington: American Psychological Association.

Fonseca, P. N., \& Salomão, N. M. R. (2006). Contingência semântica das falas materna e paterna: uma análise comparativa. Psicologia: Reflexão e Crítica, 19(1), 91-97. 
Lavelli, M., Pantoja, A. P. F, Hsu, H., Messinger, D., \& Fogel, A. (2005). Using microgenetic designs to study change processes: a relational-historical approach. In D. M. Teti (Org.), Handbook of research in developmental psychology (pp. 40-65). Baltimore: Blackwell Publishers.

Lewis, M. D. (2000). The promising of dynamic systems approaches for an integrative account of human development. Child Development, 71(1), 36-43.

Lier-DeVitto, M. F. (2005). Falas sintomáticas: um problema antigo, uma questão contemporânea. In M. M. Freire, M. H. V. Abraão, \& A. M. F. Barcelos (Orgs.), Linguística aplicada e contemporaneidade (pp. 317-327). Campinas: Pontes.

Lier-DeVitto, M. F., \& Arantes, L. (Orgs.) (2006). Aquisição, patologias e clínica de linguagem. São Paulo: Educ.

Lordelo, E. R., \& Carvalho, A. M. A. (2006). Padrões de parceria social e brincadeiras em ambientes de creche. Psicologia em estudo, 11(1), 99-108.

Lyra, M. C. D. P. (1998). Reflections on the dynamics of meaning making: Communication process at the beginning of life. In M. C. D. P. Lyra \& J. Valsiner (Orgs.), Construction of psychological processes in interpersonal communication: vol. 4. Advances in child development within culturally structured environments (pp. 225-242). Norwood: Ablex.

Lyra, M. C. D. P. (2000). Desenvolvimento como processo de mudança em um sistema de relações historicamente construído: contribuições do estudo da comunicação no início da vida. Psicologia: Reflexão e Crítica, 13(2), 257-268.

Lyra, M. C. D. P. (2006). O modelo EEA para a investigação da emergência e desenvolvimento da comunicação e do self. Bases conceituais e fundamentos teórico metodológicos. Estudos de Psicologia, 11(1), 25-33.

Lyra, M. C. D. P. (2007a). Modelo EEA: definições, unidade de análise e possíveis aplicações. Psicologia: Reflexão e Crítica, 20(1), 87-95.

Lyra, M. C. D. P. (2007b). On abbreviation: dialogue in early life. International Journal for Dialogical Science, 2, 15-44.

Lyra, M. C. D. P. \& Winegar, L.T. (1997). Processual dynamics of interactions through time: adult-child interactions and process of development. In A. Fogel, M. C. D. P. Lyra, \& J. Valsiner (Orgs.), Dynamics and indeterminism in developmental and social processes (pp. 93-109). Mahwah: Lawrence Erlbaum.

Lyra, M. C. D. P. \& Chaves, E. C. S. (2000). O desenvolvimento da comunicação no início da vida: estabelecimento, extensão e abreviação. Temas em Psicologia, 8(3), 225-240

Lyra, M. C. D. P. \& Souza, M. S. (2003). Dynamics of dialogue and emergence of self in early ommunication. In I. Josephs (Org.), Dialogicality in development: vol. 5. Advances in child development culturally structured environments (pp. 51-68). Greenwhich: Ablex.

Lyra, M. C. D. P. \& Bertau, M. (2008). Dialogical practices as basis for Self. Studia Psychologica, 8, 173-193.

Molenaar, P. C. M., \& Valsiner, L. (2005). How generalization works through the single case: A simple idiographic process analysis of an individual psychotherapy. International Journal of Idiographic Science, 1. Recuperado de http://www.scienzedellaformazione.unisalento.it/c/document_library/
get_file?folderId=2173283\&name=DLFE-37448.pdf

Piccinini, C. A., Marin, A. H., Alvarenga, P., Lopes, R. C. S., \& Tudge, J. R. (2007). Responsividade materna em famílias de mães solteiras e famílias nucleares no terceiro mês de vida da criança. Estudos de Psicologia, 12, 109-117.

Piccinini, C. A., \& Seidl-de-Moura, M. L. (2007). Observando a interação paisbebê-criança: diferentes abordagens teóricas e metodológicas. São Paulo: Casa do Psicólogo.

Prigogine, I. \& Stengers, I. (1984). Order out of chaos: man's new dialogue with nature. Nova Iorque: Batam Books.

Ribas, A. F. P., \& Moura, M. L. S. (2006). Responsividade materna: uma investigação em contexto urbano brasileiro. Revista Brasileira de Crescimento e Desenvolvimento Humano, 16(1), 01-11.

Rossetti-Ferreira, M. C., Amorim, K. S., \& Silva, A. P. S. (2000). Uma perspectiva teórico-metodológica para análise do desenvolvimento humano e do processo de investigação. Psicologia: Reflexão e Crítica, 13(2), 281-293.

Rossetti-Ferreira, M. C., Amorim, K. S., Silva, A. P. S., \& Carvalho, A. M. A. (Orgs.) (2003). Rede de significações e o estudo do desenvolvimento humano. ( $1^{\underline{a}}$ ed., v. 1). Porto Alegre: Artmed.

Sanini, C., Ferreira, G. D., Souza, T. S., \& Bosa, C. A. (2008). Comportamentos indicativos de apego em crianças com autismo. Psicologia: Reflexão e Crítica, 21(1), 60-65.

Seidl de Moura, M. L., Ribas, A. F. P., Seabra, K. C., Pessoa, L. F., Nogueira, S. E., Mendes, D. M. L. F., ...Vicente, C. C. (2008). Interações mãe-bebê de um a cinco meses: aspectos afetivos, complexidade e sistemas parentais predominantes. Psicologia: Reflexão e Crítica, 21(1), 66-73.

Thelen, E., Schöner, G., Scheier, C., \& Smith, L. B. (2001). The dynamics of embodiment: a field theory of infant perseverative reaching. Behavioral and Brain Sciences, 24(1), 1-34.

Tomasello, M., Carpenter, M., Call, J., Behne, T., \& Moll, H. (2005). Understanding and sharing intentions: The origins of cultural cognition. Brain and Behavioral Sciences, 28, 675-691.

Tomasello, M. (2008). Origins of human communication. Cambridge: MIT Press. van Geert, P. (1994). Dynamic systems of development: Change between complexity and chaos. Nova Iorque: Harvester.

van Geert, P. (1998). A dynamic systems model of basic developmental mechanisms: Piaget, Vygotsky and beyond. Psychological Review, 105, 634-677.

van Geert, 2003. Dynamic systems approaches and modeling of developmental processes. In J. Valsiner \& K. Connolly (Orgs.), Handbook of developmental psychology (pp. 640-672). London: Sage.

Vasconcelos. C. R. F., \& Rossetti-Ferreira, M. C. (2002). Crianças pequenas brincando em creche: a possibilidade de múltiplos pontos de vista. Estudos de Psicologia, 7(2), 259-270.

Vitto, M. F. L., \& Carvalho, G. M. M. (2008). O interacionismo: uma teorização sobre a aquisição da linguagem. In I. Finger \& R. M. Quadros (Orgs.), Enfoques teóricos nos estudos de aquisição da linguagem (pp. 115-146). São Paulo: Cultura Acadêmica. 
1. Não apenas mãe-bebê, mas bebê-parceiro adulto em geral.

2. O número de turnos foi estipulado a partir de sucessiva experiência com os dados e de forma comparativa, ou seja, menor no estabelecimento e na abreviação e maior na extensão.

3. Estas sucessivas etapas satisfazem um processo de familiarização do observador com os dados e correspondem, assim, ao treinamento do observador.

Maria da Conceição Diniz Pereira de Lyra, doutora em Psicologia Experimental pela Universidade de São Paulo e pós-doutora em Psicologia do Desenvolvimento Humano pela University of North Carolina e University of Utah, é professora Adjunta na Universidade Federal de Pernambuco. Endereço para correspondência: Pós-graduação em Psicologia Cognitiva, Centro de Filosofia e Ciências Humanas - $8^{\circ}$ andar - Cidade Universitária - CEP.: 50.670-901 - Recife-PE. Fones/Fax: (55-81) 33043362 (res.); (55-81) 2126-8272 - 2126-7330 (trabalho) Fax: 2126-7331.

E-mail: marialyra2007@gmail.com

Emmanuelle Christine Chaves da Silva, doutora em Psicologia Cognitiva pela Universidade Federal de Pernambuco, é Coordenadora e professora do curso de Graduação em Psicologia da Faculdade dos Guararapes e do curso de Graduação em Psicologia da Faculdade Maurício de Nassau.

E-mail: ecchaves@hotmail.com

Ana Claudia Alves da Silva, doutoranda em Psicologia Cognitiva pela Universidade Federal de Pernambuco (UFPE).E-mail: cacaunani@gmail.com 